\title{
Sudden death and acute myocarditis: a unique forensic case of double origin of coronary arteries
}

Isabella Aquila, ${ }^{1}$ Pietro Tarzia, ${ }^{1}$ Pietrantonio Ricci, ${ }^{1}$ Santo Gratteri ${ }^{2}$

'University "Magna Graecia" of Catanzaro, Institute of Legale Medicine, Viale Europa, 88100, Catanzaro, Italy, Italy

${ }^{2}$ AO MaterDomini Catanzaro, Catanzaro, Italy

\section{Correspondence to}

Dr Isabella Aquila,

isabella.aquila@hotmail.it

Accepted 7 September 2017

\section{DESCRIPTION}

The doubling of the right coronary artery is a rare congenital coronary anomaly. Generally, this malformation is asymptomatic and therefore benign. But, in some cases, it constitutes a real silent killer. The aim of this study is to show

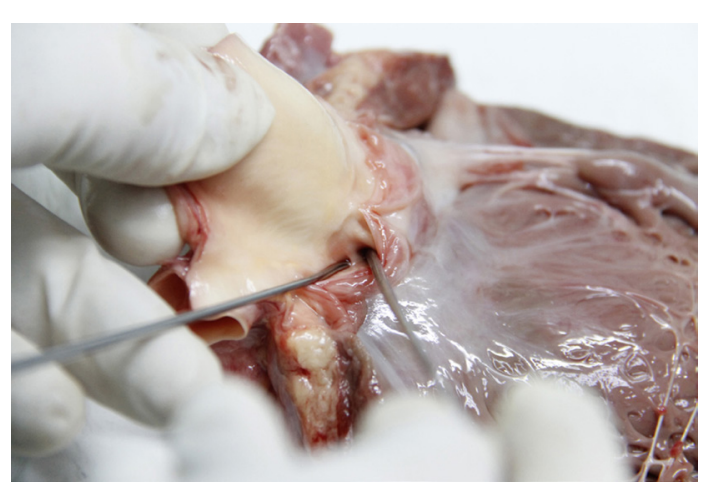

Figure 1 Doubling of the right coronary artery at autopsy.

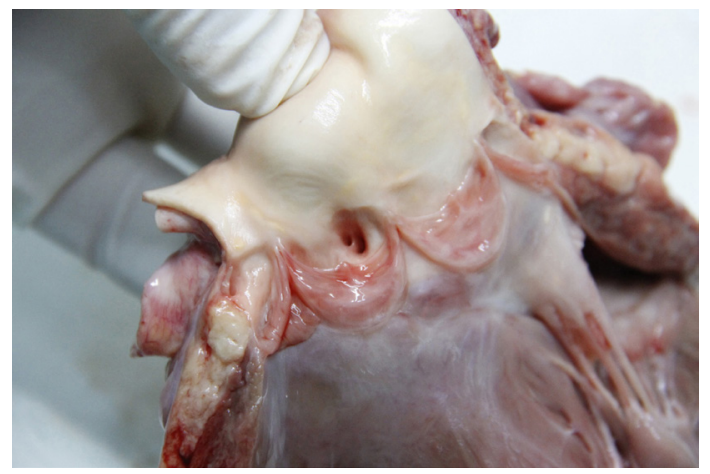

Figure 2 Identification of the duplication of the two coronary branches.

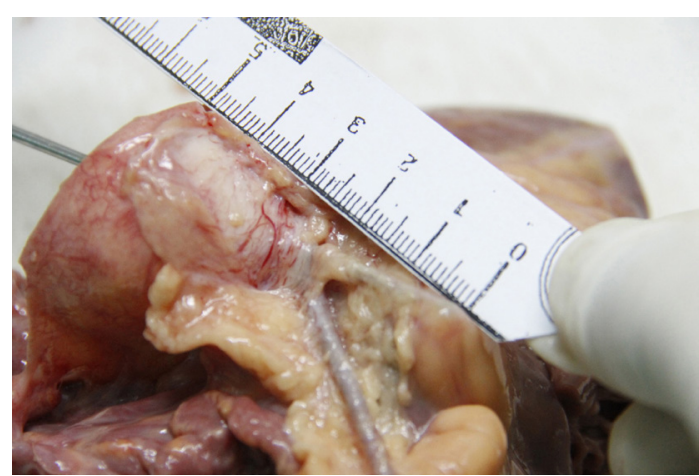

Figure 3 Intracardiac course of the doubling right coronary artery. how the double right coronary artery can cause fatal events without clinical signs of its presence. We reported the association between this anomaly and the acute necrotising myocarditis. In the forensic literature, cases of sudden death associated with the double coronary origin are not described. ${ }^{12}$

We reported the case of a sudden death in a 14-year-old girl. At autopsy, the heart showed greyish areas and the histopathological surveys demonstrated the doubling of the right coronary artery (figures 1-4). The left ventricular myocardium showed a phlegmonous exudative inflammation, large necrotic areas and interstitial leucocyte infiltration, which resulted CD68 positive to the immunohistochemical investigations. The postmortem investigation of blood with haemoculture detected the presence of Staphylococcus aureus. The cause of death was:

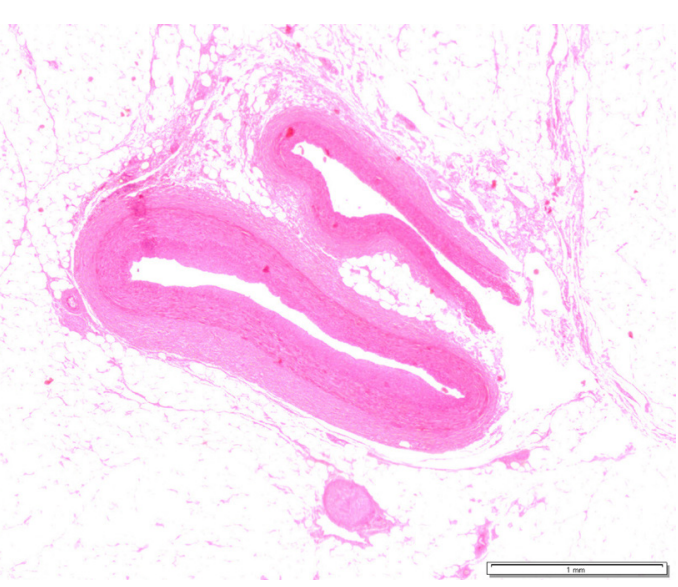

Figure 4 Histopathological image of arterial duplication.

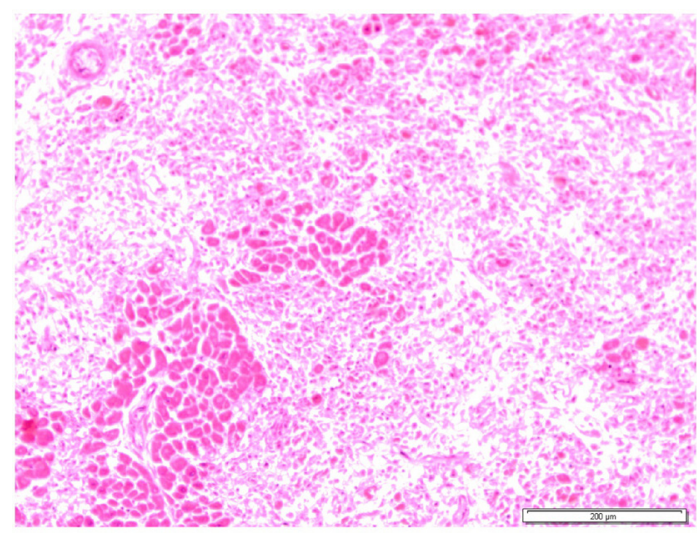

Figure 5 Histopathological image of acute myocarditis. 


\section{Learning points}

- The doubling of the right coronary artery is a rare congenital coronary anomaly.

- Generally, it is benign, but, in some cases, it can cause fatal events and it is a risk factor for other cardiac disease.

- This malformation is discovered occasionally, but it is necessary to report it because the bearers require a close cardiologic follow-up.

acute necrotising myocarditis (figure 5) with right coronary artery doubling. Probably, the coronary doubling represented an anatomical location that favoured the cardiac colonisation by $S$. aureus and so, the subsequent acute necrotising myocarditis.

This malformation is discovered occasionally during cardiac-CT or coronary angiography. It is necessary to report this anomaly because the bearers require a close cardiologic follow-up. ${ }^{3}$ For the first time, we point up how this anomaly is a risk factor for the acute myocarditis.
Contributors LA: is the forensic pathologist and the official responsible of the case. She performed the autopsy, conceived the idea and managed the whole realization of the paper. PT: has contributed through the writing of the paper. PR has contributed through the realization of the histopathological analysis and the interpretation of the data. SG: performed the autopsy with IA and managed with her the realization of the work.

Competing interests None declared.

Patient consent Obtained.

Provenance and peer review Not commissioned; externally peer reviewed.

(C) BMJ Publishing Group Ltd (unless otherwise stated in the text of the article) 2017. All rights reserved. No commercial use is permitted unless otherwise expressly granted.

\section{REFERENCES}

1 Erdogan $\mathrm{O}$, Buyuklu M, Aktoz M. Anomalous origin of the right coronary artery from the left anterior descending artery in a patient with single left coronary artery: a rare coronary artery anomaly and review of the literature. Int J Cardiol 2008;127:280-3.

2 Wilson J, Reda H, Gurley JC. Anomalous right coronary artery originating from the left anterior descending artery: case report and review of the literature. Int I Cardiol 2009;137:195-8.

3 Aquila I, Boca S, Caputo F, et al. An unusual case of sudden death: is there a relationship between thyroid disorders and fatal pulmonary thromboembolism? A case report and review of literature. Am J Forensic Med Pathol 2017;38:229-232.

Copyright 2017 BMJ Publishing Group. All rights reserved. For permission to reuse any of this content visit

http://group.bmj.com/group/rights-licensing/permissions.

BMJ Case Report Fellows may re-use this article for personal use and teaching without any further permission.

Become a Fellow of BMJ Case Reports today and you can:

- Submit as many cases as you like

- Enjoy fast sympathetic peer review and rapid publication of accepted articles

- Access all the published articles

Re-use any of the published material for personal use and teaching without further permission

For information on Institutional Fellowships contact consortiasales@bmjgroup.com

Visit casereports.bmj.com for more articles like this and to become a Fellow 